\title{
Rotundabaloghia (Rotundabaloghia) dogani sp. nov. from Hong Kong (Acari: Mesostigmata: Rotundabaloghiidae)
}

\author{
Jenő KONTSCHÁN (1D \\ Plant Protection Institute, Centre for Agricultural Research, H-1525 Budapest, P.O. Box 102, Hungary \\ e-mail: kontschan.jeno@atk.hu
}

Received: 12 December 2020

Accepted: 30 December 2020

Available online: 27 January 2021

ABSTRACT: Rotundabaloghia (Rotundabaloghia) dogani sp. nov. is described based on three females and one male collected from soil in Tai Po Kau Nature Reserve, in Hong Kong. The new species differs from the other species from the subgenus Rotundabaloghia in the shape and length of the ventral setae.

Keywords: Mite, Taxonomy, South-East Asia.

Zoobank: http://zoobank.org/4C72C121-E7E2-42F2-A69A-4C17737D73AD

\section{INTRODUCTION}

The Rotundabaloghia (Rotundabaloghia) Hirschmann, 1975 is an endemic subgenus in South-East Asia and in Austral-Asian region, the members of this taxon are described from New Guinea, suthern parts of Japan, Taiwan, Philippines, Indonesia and Hong Kong (Kontschán, 2010, 2015, Kontschán \& Kiss, 2015). This subgenus is well characterized by the three or four pairs of short and needle-like setae on rows $j-J$ on dorsal body among the lot of long and apically pilose setae, contrary with the sistergroup (Rotundabaloghia (Circobalogia) Kontschán, 2010) where these short and smooth dorsal setae are absent (Kontschán, 2010).

Till today only three Uropodina mites are presented from area of Hong Kong, all from the family Rotundabaloghiidae Kontschán, 2010 (Kontschán, 2015) and only one species belongs to this subgenus $(R$. $(R$.) hongkongensis Kontschán, 2015).

During my last visit to Natural History Museum of Geneva some soil samples from Hong Kong were also investigated. One of the samples contained several specimens of rotundabaloghiid mites, described herein as second species from this subgenus from Hong Kong.

\section{MATERIALS AND METHODS}

The specimens examined were cleared in lactic acid for a week and afterwards, the specimens were investigated on half-covered deep slides with a Leica 1000 microscope. Drawings were made with the aid of a drawing tube on a Leica 1000 microscope. All measurements and the scale bars in the figures are given in micrometres $(\mu \mathrm{m})$.

All specimens are stored in ethanol and deposited in the Natural History Museum of Geneva.

Abbreviations

$v=$ ventral setae, $s t=$ sternal setae, $a d=$ adanal setae, $p=$ pores, $l f=$ lyriform fissures.

\section{RESULTS}

Rotundabaloghia (Rotundabaloghia) dogani sp. nov.

Zoobank: http://zoobank.org/3083E06F-F613-4729B2B9-9479030B463C

(Figures 1-7).

Diagnosis. Dorsal shield covered by oval pits, dorsal setae long and apically pilose except three pairs of short and needle-like setae on central area. All ventral setae smooth and needle-like, setae st 1 short, setae $v 2$ and $v 6$ shorter than $v 7$ and $v 8$.

Material examined. Holotype. Female. SBH-96/17, Hong Kong (New Territories), Tai Po Kau Nature Reserve, after the big picnic area soil sampled near a dead but still standing tree, $150 \mathrm{~m}$ a.s.l.; 9.XII.1996; leg. B. Hauser (soil extraction by means of a Berlese funnel in Geneva). Paratypes. Two females and one male, collection data as in holotype.

Description

Female ( $n=3)$.

Description. Length of idiosoma 325-335, width 265-280. Shape circular, posterior margin rounded, colour reddish brown.

Dorsal idiosoma (Fig. 1). Marginal and dorsal shields fused. Majority of dorsal setae basally curved and apically pilose (ca 36-39), except three pairs of short (ca 9-10) and smooth setae on rows $j-J$. Four pairs of lyriform fissures and two pairs of pore-like organs situated on central and centrolateral areas of dorsal shield. Surface of dorsal shield covered by oval pits (ca $4-5 \times 4-6$ ).

Ventral idiosoma (Fig. 2). Sternal shield covered by some oval pits (ca $4-5 \times 4-5$ ). All sternal setae smooth and needle-like, st 1 and $s t 4$ short (ca 4-5), st2 and st3 long (ca 711). Setae st1 situated at level of anterior margin of coxae II, st2 at level of posterior margin of coxae II, st3 at level of central area of coxae III, St4 at level of anterior margin of 
coxae IV. All ventral setae smooth and needle-like, $v 2$ and v6 ca 8-10, v7 ca 17-18, v8 ca 23-25 and adanal setae ca 16-17 long. Setae $v 2$ situated near basal edges of genital shield, $v 7$ and $v 8$ situated at level of setae $a d$. Setae $v 6$ situated between $v 2$ and $v 8$. Setae $a d$ placed lateral to anal opening, at level of its anterior margin. Ventral shield covered by oval pits (ca $5-6 \times 5-6$ ), but smooth around anal opening. One pair of lyriform fissures situated close to setae v2. Peritremes (Fig. 2) with a short straight poststigmatid part and a longer hook-shaped prestigmatid part. Stigmata situated between coxae II and III. Genital shield wide, linguliform (108-110 long and 55-58 wide at base), without apical process. Surface of genital shield covered by oval pits (ca 4-6×5-6). Pedofossae deep, their surface smooth, separate furrows for tarsi IV present. Base of tritosternum narrow, vase-like, tritosternal laciniae smooth, subdivided into three smooth branches in its distal half.

Gnathosoma. Corniculi horn-like, internal malae smooth and as long as corniculi. Hypostomal setae h1 long (ca 913), smooth and needle-like. Other setae and other parts not visible, covered by coxae I.

Legs (Figs 3-6). All legs with smooth and needle-like setae, the claws on first leg absent. All femora bearing flaplike ventral processes. Leg I 190-195, leg II 195-205, leg III 195-205, leg IV 200-210.

Male $(n=1)$.

Length of idiosoma 325, width 275.

Dorsal idiosoma. Ornamentation and chaetotaxy of dorsal shield as for female.

Ventral idiosoma (Fig. 7). Four pairs of sternal setae (st1st4) situated anterior to genital shield, st5 placed lateral to genital opening. Setae st1, st4 and st5 short (ca 4-7), st2 and st3 long (ca 12-13) all sternal setae smooth and needle-like. All ventral setae smooth and needle-like, $v 2$ and $v 6$ ca $13-15, v 7$ and $v 8$ ca $22-26$ and adanal setae ca 1718 long. Positions of ventral setae same as in females. Ventral shield covered by oval pits (ca $4-5 \times 4-6$ ), but smooth around anal opening. One pair of lyriform fissures situated close to setae $v 2$. Other characters as in female. Genital shield oval $(27 \times 28)$ and situated between coxae IV.

Larva and nymphs. Unknown.

Etymology. I dedicated the new species to my dear friend and the founder of the Acarological Studies, Dr. Salih Doğan.

Remark. Currently only three rotundabaloghiid species were described from Hong Kong (Kontschán, 2015), namely Angolubaloghia staryi Kontschán, 2015, Rotundabaloghia (Rotundabaloghia) hongkongensis Kontschán, 2015 and Depressorotunda (Depressorotunda) taurina Kontschán 2015. The new species differs in some characters from the previously described ones. The $R$. (R.) doga$n i$ does not have ventral cavity, contrary with the $D$. (D.) taurina, where it is well-developed. The genital shield of the new species is linguliform, but it is triangular in the case of $A$. staryi. The setae $v 8$ is very short and $v 2$ very long in $R$. (R.) hongkongensis, but the new species bears short $v 2$ and long $v 8$ setae.

Updated key for the Rotundabaloghia (Rotundabaloghia) species (modified, after Kontschán, 2015).

1 , Setae $v 8$ smooth. 2

- Setae $v 8$ not smooth 8

2 , Setae $v 8$ shorter than other ventral setae ........................... 6

- Setae $v 8$ similar in length to $v 7$.............................................. 3

3 , Setae $v 2$ and $v 6$ shorter than $v 7$ and $v 8$

$R .(R$.$) dogani sp. nov.$

- Setae $v 2$ and $v 6$ similar in length to $v 7$ and $v 8$................... 4

4 , Setae $v 7$ longer than other ventral seta .. R. (R.) kaszabi Hirschmann, 1975

- Setae $v 7$ as long as other ventral setae ................................ 5

5 , Scupltural patter between setae $v 7$ present R. (R.) makilingoides Hirschmann \& Hiramatsu, 1992

- Scupltural patter between setae $v 7$ absent

R. (R.). makilingensis Hirschmann \& Hiramatsu, 1992

6 , Setae $v 6$ as long as $v 8$.

R. (R.) hongkongensis Kontschán, 2015

- Setae $v 6$ longer than $v 8$.

7, Setae $v 8$ as long as $a d$.......R. (R.) korsosi Kontschán, 2008

- Setae $v 8$ shorter than ad

... (R.) hirschmanni Hiramatsu, 1977

8, Setae ad pilose R. (R.) baloghi Hirschmann, 1975

- Setae ad smooth ... 9

9 , Setae $v 7$ pilose …..................................................................

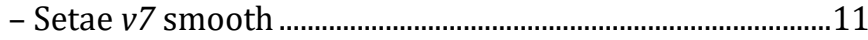

10 , Setae $s t 1$, st 2 and $s t 3$ much longer $(10 \times)$ than $s t 4$ R. (R.) macroseta Hirschmann, 1975

-Setae st1, st2 and st3 not much longer $(4 \times)$ than st4 R. (R.) mahunkai Hirschmann, 1975

11 , Seate st 1 longer and wider than st2 and st3. $R$. (R.) monomacroseta Hirschmann, 1975

- Setae st 1 not longer and wider than st2 and st3 .....12

12 , Setae $v 7$ two times longer than ad.....

R. (R.) kaszabisimilis Hirschmann, 1975

- Setae $v 7$ as long as ad .......R. (R.) pilosa Hirschmann, 1975

\section{Statement of ethics approval}

Not applicable.

Funding

There is no fund for the present study.

\section{Conflict of interest}

The author declares that there is no conflict of interest regarding the publication of this paper.

\section{Acknowledgements}

I am very grateful to Dr. Peter Schwendinger (Natural History Museum of Geneva) for his kind hospitality during my stay in Geneva. 


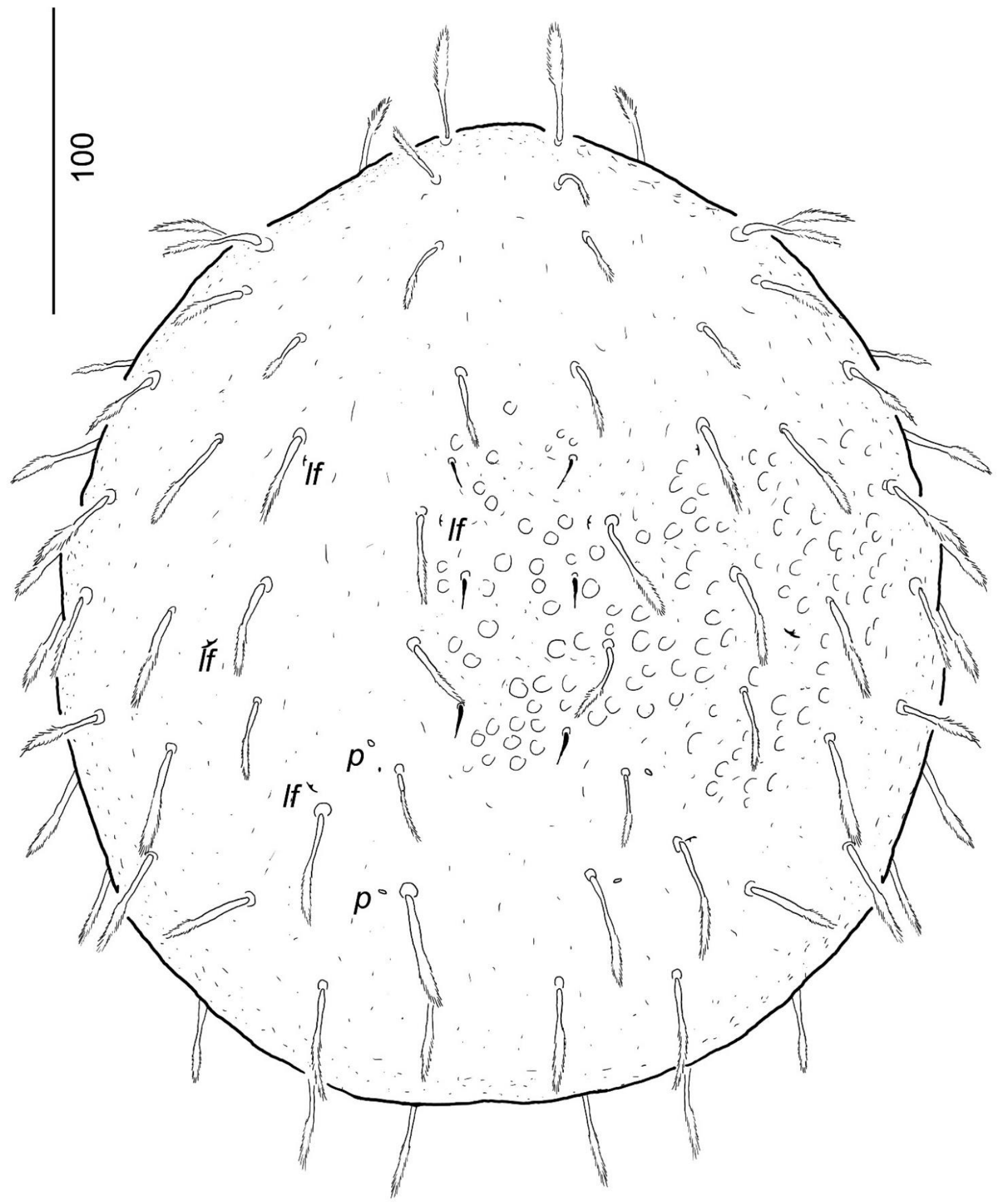

Figure 1. Dorsal view of Rotundabaloghia (Rotundabaloghia) dogani sp. nov. female, holotype.

\section{REFERENCES}

Hiramatsu, N. 1977. Gangsystematik der Parasitiformes. Teil 239. Teilgang einer neuen Rotundabaloghia-Art aus Japan (Dinychini, Uropodinae). Acarologie, Schriftenreihe für Vergleichende Milbenkunde, 23: 1920. [In German]

Hirschmann, W. 1975. Gangsystematik der Parasitiformes. Teil 203. Teilgänge, Stadien von 16 neuen Rotundabaloghia-Arten (Dinychini, Uropodinae). Acarologie, Schriftenreihe für Vergleichende Milbenkunde, 21: 28-34. [In German]

Hirschmann, W. and Hiramatsu, N. 1992. 34 Rotundabaloghia Arten aus Asien (Japan, Neuguinea, Philippinen, Borneo) (Dinychini, Uropodinae). Acarologie, Schriftenreihe für Vergleichende Milbenkunde, 39: 9-25. [In German] 


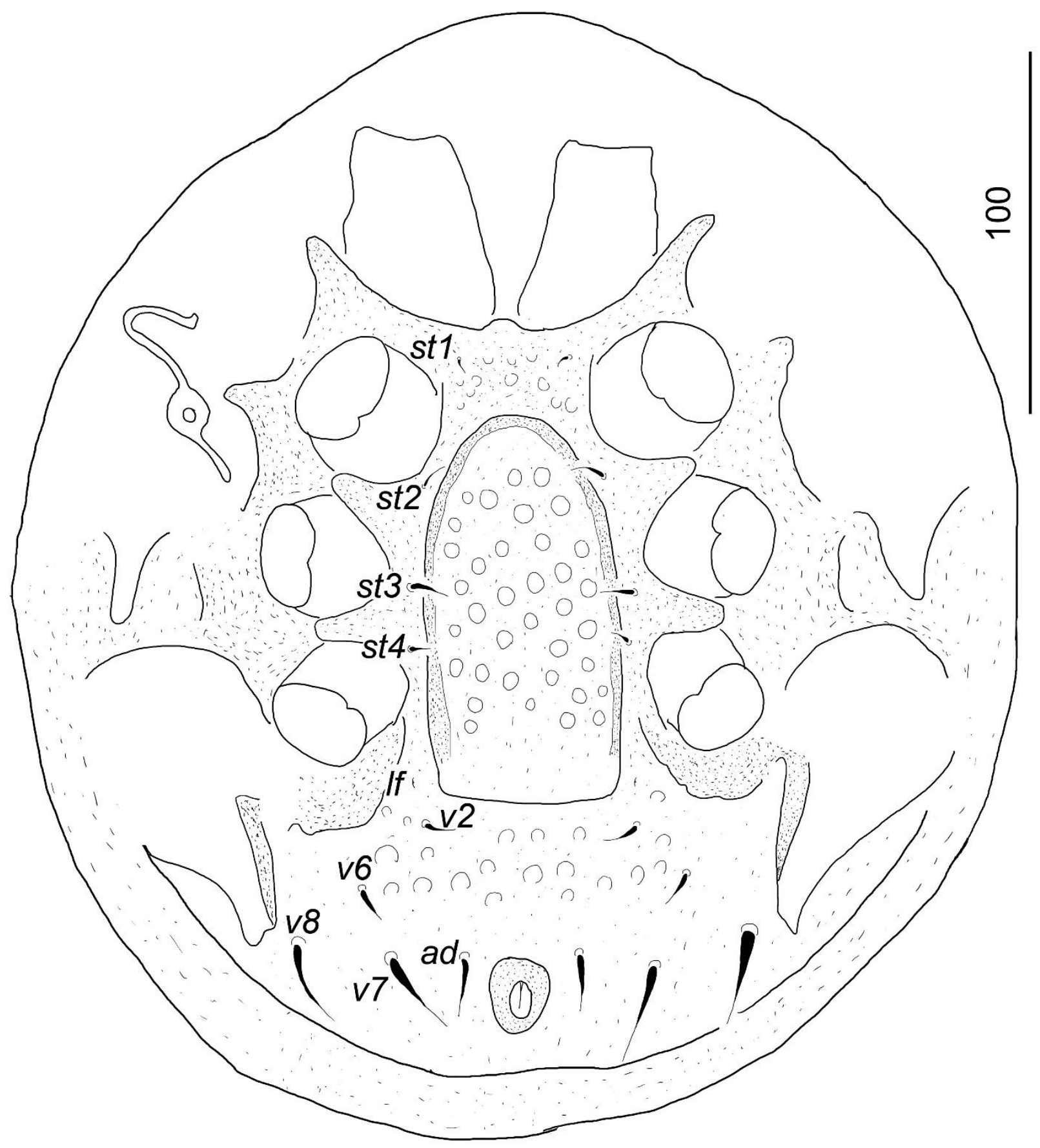

Figure 2. Ventral view of Rotundabaloghia (Rotundabaloghia) dogani sp. nov. female, holotype.

Kontschán, J. 2008. Rotundabaloghia korsosi sp. nov. (Acari: Uropodina) from Taiwan. Collection and Research, 21: 45-51.

Kontschán, J. 2010. Rotundabaloghiid mites of the world (Acari: Mesostigmata: Uropodina). Ad Librum Kiadó, Budapest, Hungary, 116 pp.
Kontschán, 2015. Three new rotundabaloghid mites (Acari: Uropodina) from Hong Kong. Revue suisse de Zoologi, 122 (1): 45-54. doi: 10.5281/zenodo.14581

Kontschán, J. and Kiss, B. 2015. Five new rotundabaloghiid mites (Acari: Uropodina) from South-East Asia. Zootaxa, 4021 (4): 515-528. doi: 10.11646/zootaxa.4021.4.2 


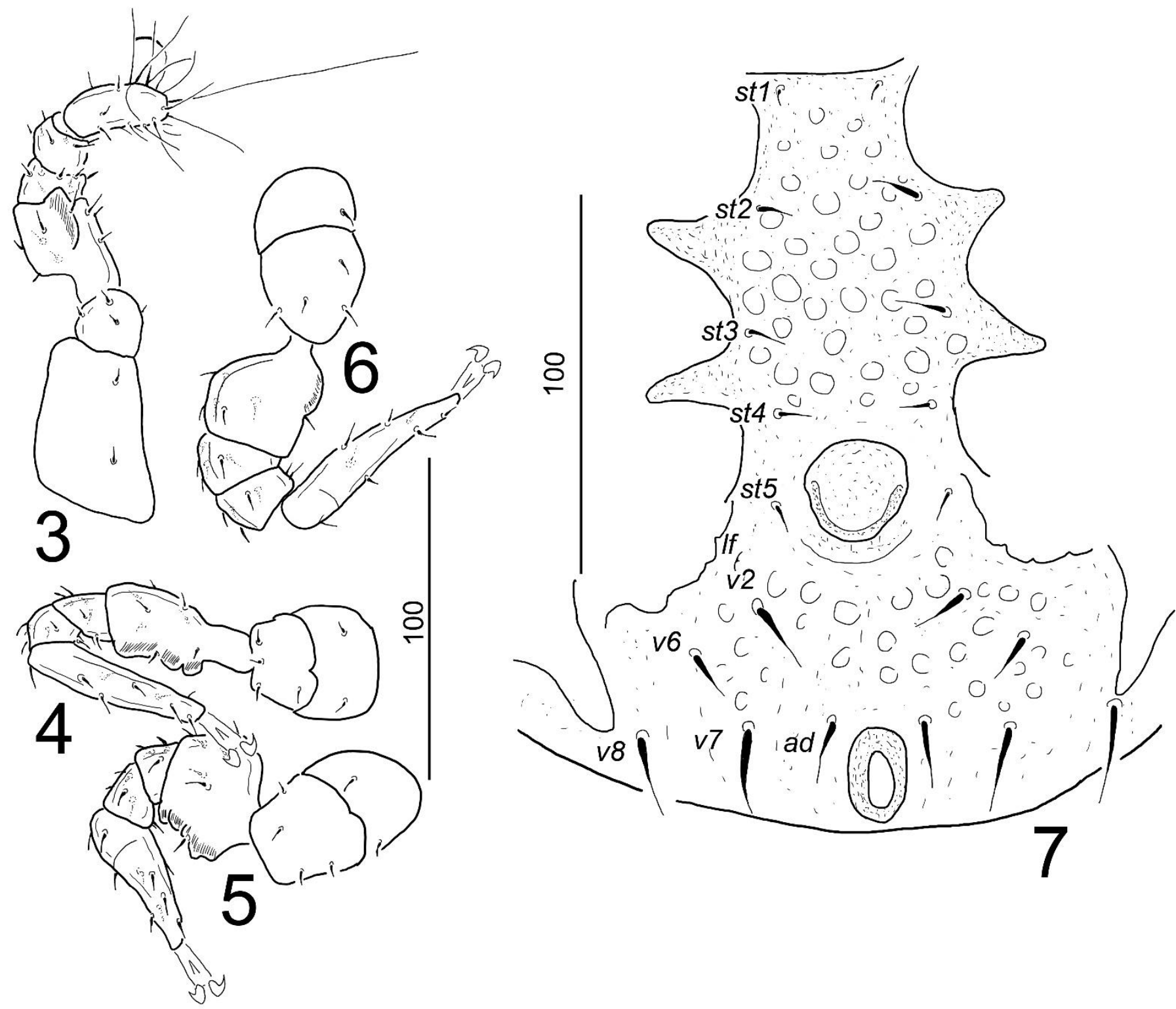

Figures 3-7. Rotundabaloghia (Rotundabaloghia) dogani sp. nov. female, holotype. 3. Leg I. in ventral view, 4. Leg II in ventral view, 5. Leg III in ventral view, 6. Leg IV in ventral view, 7. Intercoxal area of male paratype. Rotundabaloghiidae). Acarological Studies, 3 (1): 32-36. 